\title{
Trichoscopic findings of trichotillomania: new observations
}

\author{
Ömer Faruk Elmas', Mahmut Sami Metin² \\ ${ }^{1}$ Department of Dermatology and Venereology, Faculty of Medicine, Ahi Evran University, Kırşehir, Turkey \\ ${ }^{2}$ Department of Dermatology and Venereology, Batman Medical Park Hospital, Batman, Turkey \\ Adv Dermatol Allergol 2020; XXXVII (3): 340-345 \\ DOI: https://doi.org/10.5114/ada.2020.96295
}

\begin{abstract}
Introduction: Recently, dermoscopy of the hair and scalp, also known as trichoscopy, has become an important diagnostic tool in the diagnosis of hair diseases. There are few studies describing trichoscopic findings of trichotillomania (TTM).

Aim: To evaluate and identify specific trichoscopic features of TTM.

Material and methods: The study included 20 patients diagnosed with TTM on the basis of the clinical history, physical examination and trichoscopic findings. All of the trichoscopic images of the patients were retrospectively reviewed and the findings identified were recorded. Descriptive statistical analysis was performed.

Results: The findings detected were broken hairs at different levels (100\%), short vellus hairs ( $90 \%)$, black dots (85\%), trichoptilosis (75\%), V hair (70\%), hair powder (65\%), yellow dots (55\%), Mace hair (45\%), coiled hairs (45\%), exclamation mark hair (40\%), blood spots (40\%), branched hair (40\%), angulated hair (40\%), concentric hair (35\%), flame hair (30\%), and tulip hair (25\%).

Conclusions: Here we have documented trichoscopic findings of TTM retrospectively. Trichoptilosis, $V$ hair and hair powder were the most frequent relatively specific findings. We tried to define novel findings that we named branched hair and concentric hair. We also detected Mace hair in 9 cases. Mace hair was previously described just in 3 cases of TTM in a case study. Angulated hairs, to the best of our knowledge, were also firstly described for TTM in the present study. Lack of a comparison group is the main limitation of the study.
\end{abstract}

Key words: branched hair, dermoscopy, trichoscopy, trichotillomania.

\section{Introduction}

Trichotillomania (TTM) is a form of alopecia resulting from traumatic compulsion to pull out one's own hairs. Clinically, patients present with patchy alopecia showing different levels of broken hairs and other clues associated with trauma. TTM may involve any hairy area including beard, eyebrows, eyelashes etc. The entity commonly affects children but it can also be seen in adult males and females. The exact diagnosis of the disease is usually not easy and the main differential diagnosis is alopecia areata (AA) [1-3].

- TTM is considered to be a kind of an obsessive compulsive disorder. DSM-V (Diagnostic and Statistical Manual of Mental Disorders, Fifth Edition) criteria for TTM are as follows [4]:

- Hair loss caused by recurrent pulling out of hair.

- The individual must have tried to decrease or stop the hair-pulling behaviour.
- Hair pulling causes significant distress or impairment in at least one area of functioning.

- Other possible medical causes of hair loss should be excluded.

- The hair pulling cannot be better explained by a clinical manifestation of another mental disorder.

Recently, dermoscopy of the hair and scalp, also known as trichoscopy, has become an important diagnostic tool in the diagnosis of hair diseases. There are few studies describing trichoscopic findings of TTM and these findings mainly include different levels of broken hairs, trichoptilosis and coiled hairs. Tulip hairs, flame hairs, $V$ hairs, hair powder and Mace hairs are the other recently described findings $[3,5,6]$.

\section{Aim}

The aim of this study is to evaluate and identify specific trichoscopic features of TTM.

Address for correspondence: Ömer Faruk Elmas MD, Department of Dermatology and Venereology, Faculty of Medicine, Ahi Evran University, Kırşehir 40000, Turkey, phone: +90 5330260679, e-mail: omerfarukmd@gmail.com Received: 5.10.2018, accepted: 23.10.2018. 


\section{Material and methods}

The study included 20 patients diagnosed with TTM on the basis of the clinical history, physical examination and trichoscopic findings, in 1 year. Trichoscopy was performed using a polarized-light handheld dermoscope with 10-fold magnification (DermLite pro HR II; 3Gen, San Juan Capistrano, CA). At least four trichoscopic images of each case were taken from different areas of hair loss, using a camera phone with a high resolution (iPhone 7 plus, Apple, California, USA). All of the trichoscopic images were retrospectively reviewed and the findings identified were recorded. Descriptive statistical analysis was performed. The study was approved by the local clinical research ethics committee.

\section{Results}

The study included 12 male and 8 female patients. The mean age was $15 \pm 6.6$ years. The mean disease $\mathrm{du}$ ration was $4.5 \pm 3$ months. The findings detected were broken hairs at different levels (100\%) (Figures 1 A, B, 2 A), short vellus hairs (90\%), coiled hairs (45\%), Mace hair (45\%) (Figures 1 A, B, 2 B, 3 A, B, 4 A), black dots (85\%) (Figure 4 B), trichoptilosis (75\%) (Figure $3 A$ ), $\checkmark$ hair (70\%) (Figure $2 \mathrm{~A})$, hair powder (65\%) (Figure 1B), yellow dots (55\%) (Figure $1 \mathrm{~B}$ ), exclamation mark hair (40\%) (Figure 4 B), blood spots (40\%) (Figures 1 A, B, 3 B), flame hair (30\%) (Figure 4 B), tulip hair (25\%) (Figure $4 \mathrm{~B}$ ), concentric hair (35\%) (Figures $2 \mathrm{~A}, 4 \mathrm{~A}$ ), angulated hair (40\%) (Figures 2 A, B, 3 A, 4 B) and branched hair (40\%) (Figures $2 \mathrm{~A}, 4 \mathrm{~A})$. The number and frequency of the detected trichoscopic findings along with the detailed explanations are shown in Table $1[3,5,6]$.

\section{Discussion}

There are very few studies about trichoscopic findings of TTM apart from limited case studies. Broken hairs at different levels, trichoptilosis (split ends), coiled hairs and black dots were the first described features [7-10]. The most comprehensive study about trichoscopy of TTM in which 44 cases were evaluated has been conducted by Rakowska et al. [3]. The other following studies evaluated 23 and 10 cases of TTM $[6,11]$. In this context, our study, to the best of our knowledge, is one of the most comprehensive studies.

Recently, Rakowska et al. have described 4 new trichoscopic findings of TTM which were flame hairs, $V$ sign/V hair, tulip hairs, and hair powder [3]. Then, Malakar et al. defined new findings and they named it "Mace sign" [5].

In the present study, we evaluated 20 cases of TTM in terms of all these findings. The most common finding was broken hairs at different levels which were detected in all the cases. The frequency of this finding was also nearly $100 \%$ in the previous studies [3, 6, 11]. Broken hairs, however, are not specific to TTM. It can also be seen in alopecia areata and tinea capitis [3]. Short vellus hair (90\%), and black dots (85\%) were the other nonspecific findings.

Trichoptilosis (75\%) was the most frequent relatively specific finding. In the study of Khunkhet et al., the frequency of this finding was nearly $73 \%$ [5]. In the study of Rakowska et al., trichoptilosis was observed in $34 \%$ of the cases with TTM. This rate was just $2 \%$ in the cases with $\mathrm{AA}[3]$.

Here we introduced a novel finding which we named branched hair. Branched hair can be defined as a hair
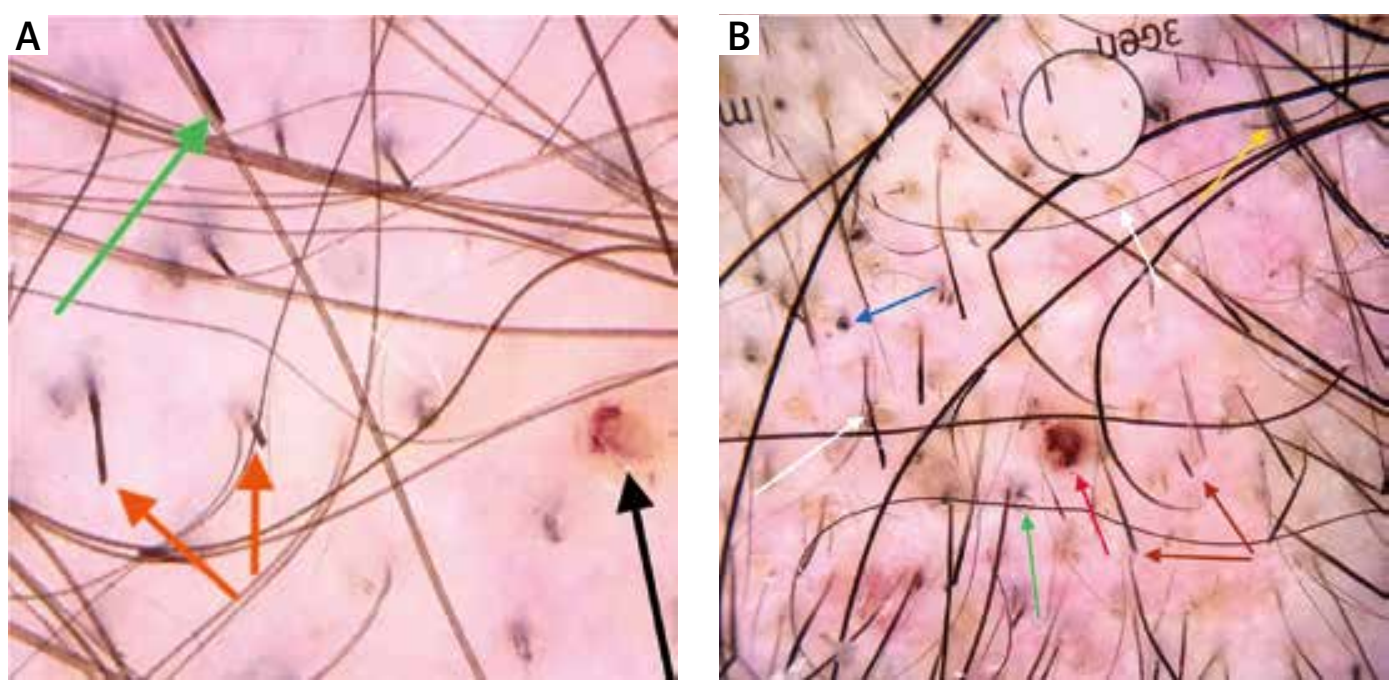

Figure 1. A - Mace hair (green arrow), broken hairs at different levels (orange arrow), follicular haemorrhage (black arrow). B - Hair powder (circle), yellow dot (white arrow), Mace hair (yellow arrow), follicular haemorrhage (red arrow), broken hairs at different levels (orange arrows), regrowing pig tail hair (green arrow) 

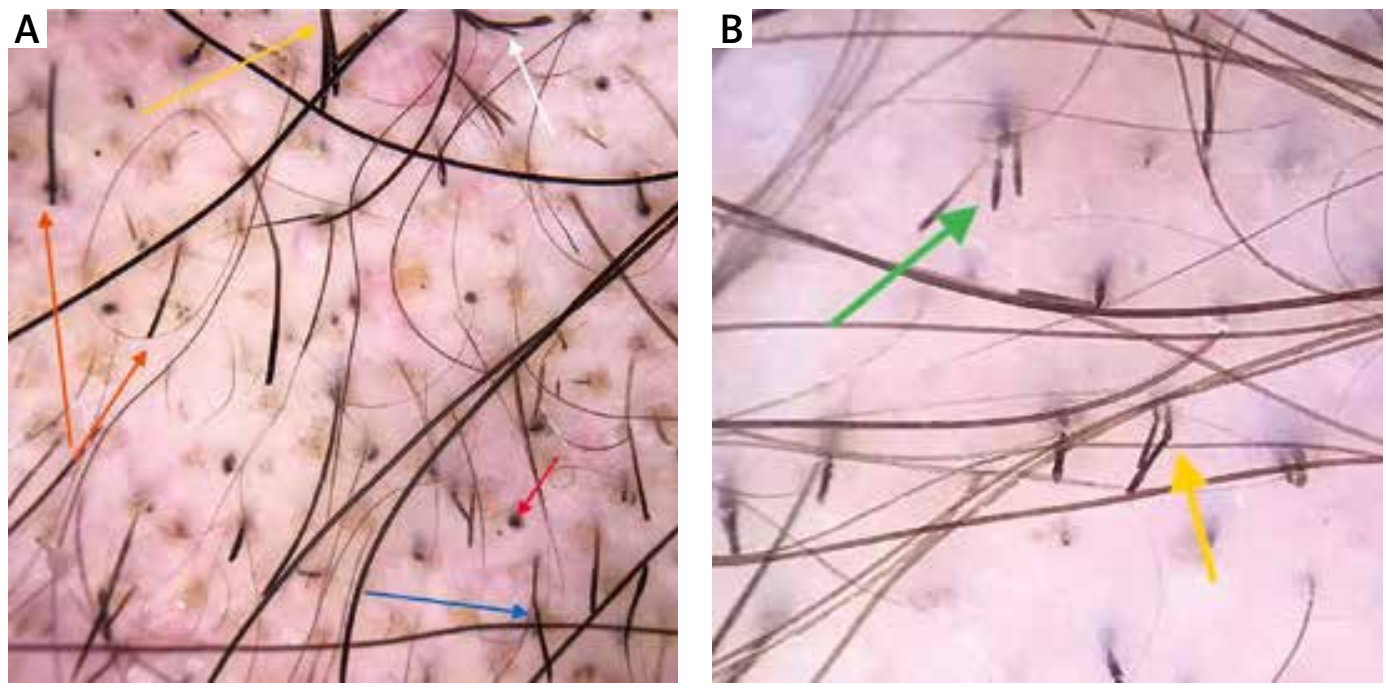

Figure 2. A - V hair (yellow arrow), broken hairs at different levels (orange arrows), branched hair (white arrow), concentric hair (red arrow), angulated hair (blue arrow). B - Mace hair (green arrow), angulated hair (yellow arrow)
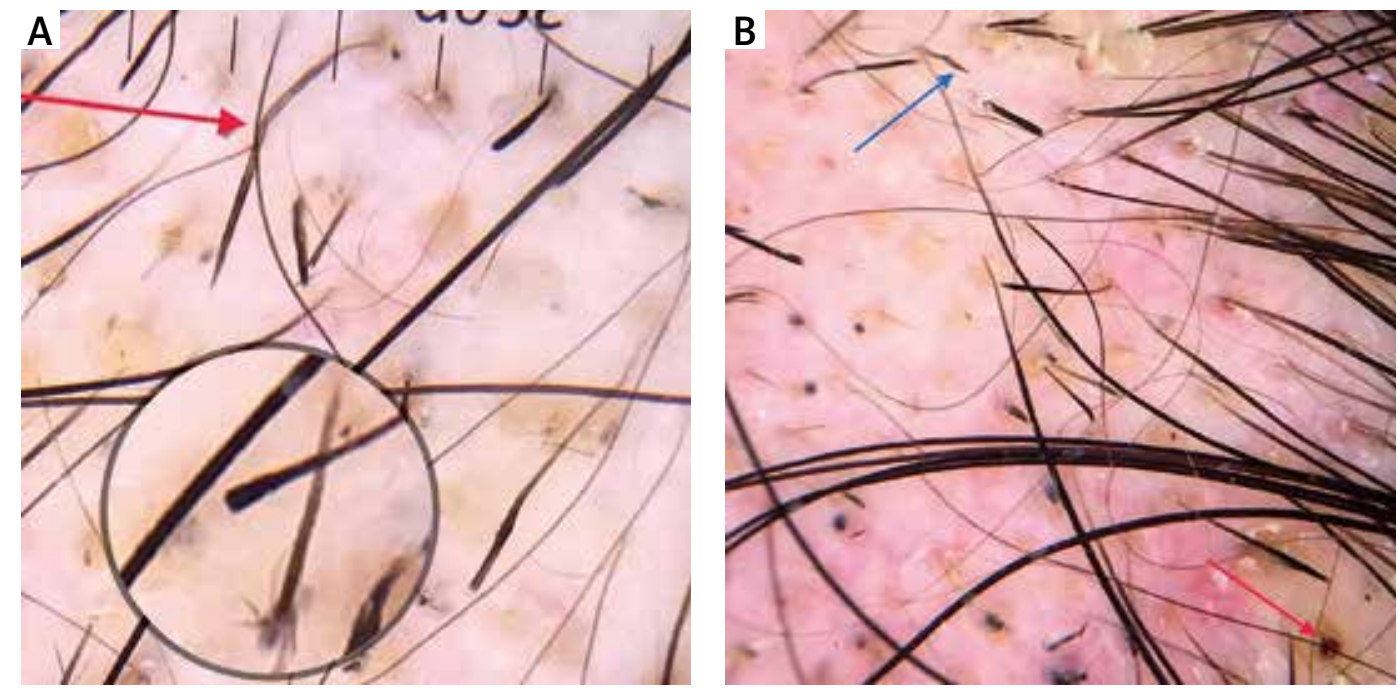

Figure 3. A - Angulated hair (red arrow), trichoptilosis (circle), Mace hair (circle). B - Mace hair (blue arrow), follicular haemorrhage (red arrow)

shaft with obliquely detached pieces. It is different from trichoptilosis which is described as "split ends" and is observed in very short hairs in TTM patients. We hypothesized that the branched hair sign may be caused by pushing and manipulating the hair shaft linearly from the distal end to the proximal end.

Another finding which was first described for TTM in the present study was concentric hair, which can be described as a broken hair presenting as a central black dot surrounded with a black circle. We suggest that concentric hair may be caused by attenuation of hair cortex associated with repetitive trauma.

$\checkmark$ hair (70\%) and tulip hair (25\%) were the other relatively specific findings. $V$ hair results from simultaneous pulling of 2 or more hairs emerging from one follicular unit [3]. Tulip hair is created when a hair shaft fractures diagonally [3]. In our study, the frequency of $V$ hair was considerably higher than in the previous studies [3, 6, 11]. In the study of Rakowska et al., $48 \%$ of the cases with TTM and $10 \%$ of the cases with AA showed tulip hairs. In the same study, $\vee$ hair was observed in $57 \%$ of the cases with TTM and just $0.6 \%$ of the cases with AA [3].

We detected Mace sign in 9 (45\%) cases. Mace sign is a most recently described trichoscopic sign in a case study. Malakar et al. described it as "broken terminal hairs uniform in diameter and pigmentation with a bulging distal end" in three cases. The bulging distal end represents the head of a mace and the longitudinal proximal 

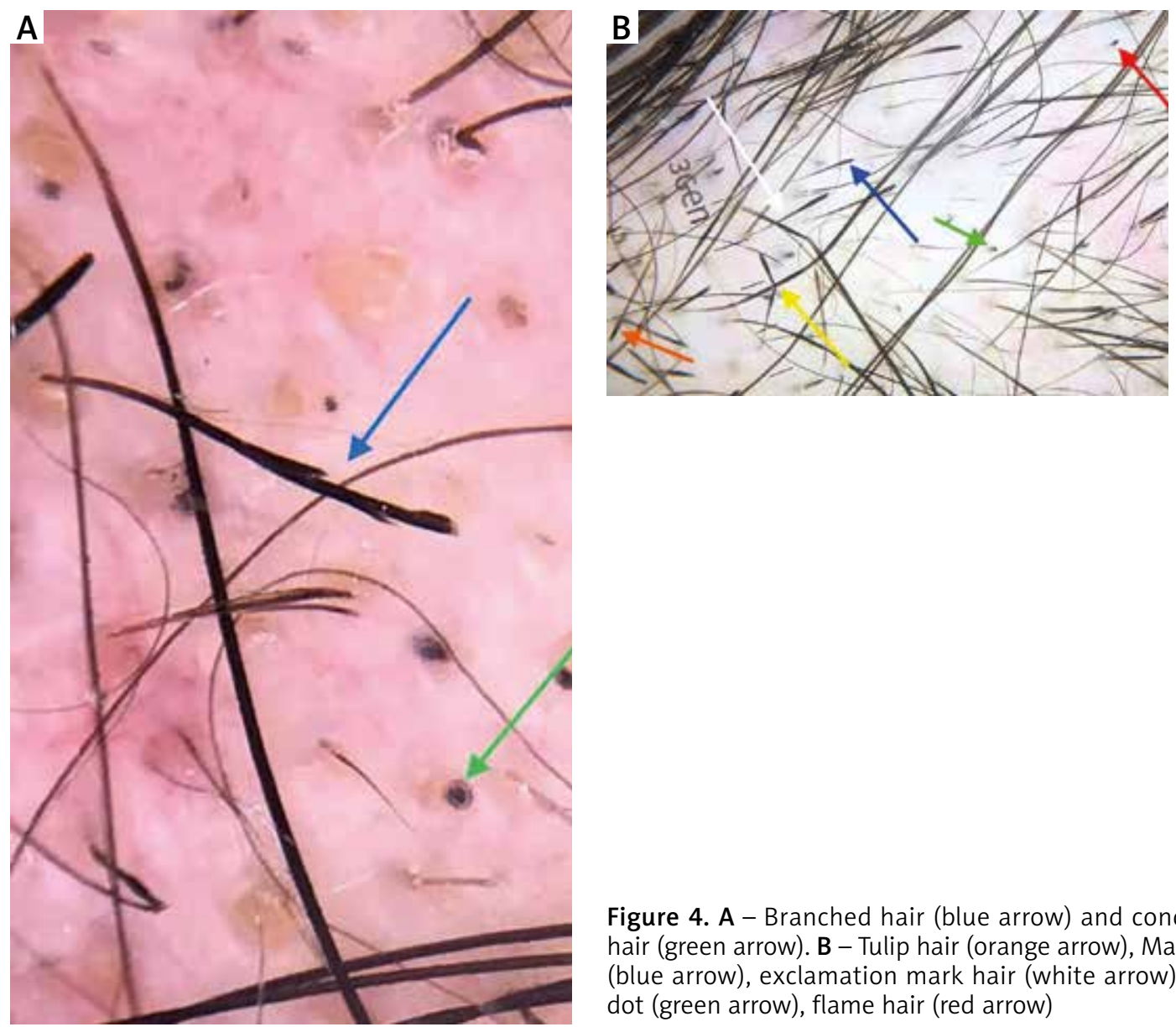

Figure 4. A - Branched hair (blue arrow) and concentric hair (green arrow). B - Tulip hair (orange arrow), Mace hair (blue arrow), exclamation mark hair (white arrow), black dot (green arrow), flame hair (red arrow)

Table 1. Number and frequency of the detected trichoscopic findings

\begin{tabular}{lcl}
\hline Trichoscopic features & $\begin{array}{c}\text { Cases } \\
n(\%)\end{array}$ & Description \\
\hline Broken hairs at different levels & $20(100)$ & Numerous hairs broken in different levels among normal terminal hairs \\
\hline Short vellus hair & $18(90)$ & Pale, non-medullated thin and short hairs \\
\hline Black dots & $17(85)$ & Broken hair at the level of scalp \\
\hline Trichoptilosis & $15(75)$ & Split ends commonly observed in very short hairs \\
\hline V hair & $14(70)$ & Two or more hairs broken at the same length emerging from one follicle \\
\hline Hair powder & $13(65)$ & Almost entirely damaged hair shaft which shows only sprinkled dots \\
\hline Yellow dots & $11(55)$ & Empty follicular openings filled with keratotic material and sebum \\
\hline Mace hair & $9(45)$ & Broken terminal hairs with a bulging distal end \\
\hline Coiled hair & $9(45)$ & Irregular coil shaped hairs resulting from pulling force \\
\hline Exclamation mark hair & $8(40)$ & Hairs with a thin-pale proximal end and a thick-darker distal end. \\
\hline Follicle haemorrhages & $8(40)$ & Blood spots associated with forced plucking \\
\hline Branched hair & $8(40)$ & A hair shaft with obliquely detached pieces \\
\hline Angulated lines & $8(40)$ & Fractured hairs forming a sharp angle along the hair shaft \\
\hline Flame hair & $6(30)$ & Thin, wavy shaped hair residues \\
\hline Tulip hair & $5(25)$ & Short hairs with a slightly thinner proximal end than the distal end and tulip-like \\
\hline Concentric hair & $7(35)$ & A broken hair presenting as a central black dot surrounded with a black circle \\
\hline
\end{tabular}


end represents the handle of the mace. Malakar et al. suggest that Mace sign may be caused by splaying of the distal end of the hair. Mace sign is different from tulip hair, which can be described as a black mark at the tip of the hair resembling a tulip flower. Malakar et al. suggest that the Mace sign is the most specific trichoscopic finding of TTM [5]. We also argue that this finding is quite specific for TTM.

Angulated hairs is another novel term which was described as "fractured hairs forming a sharp angle along the hair shaft, regardless of the amount of fracture sites" in Khunkhet et al.'s study. This sign was detected in $26.9 \%$ of AA cases and none of the TTM cases showed angulated hairs in the above-mentioned study. Here we detected this sign in 8 cases with TTM (40\%) [6]. So it can be said that angulated hair is not a specific sign for AA or TTM.

Coiled hairs can be described as proximal hair parts remaining attached to the scalp after the distal part has been pulled. Coiled hair is different from re-growing pig tail hair (Figure 1 B) which has irregular appearance and frayed end $[3,11]$. Coiled hair is accepted to be one of the specific findings of TTM. In our study, $45 \%$ of the cases showed coiled hairs.

Flame hair is a specific finding for TTM which was firstly described by Rakowska et al. as wavy thin hair. The frequency of flame hair was 30\% (6 cases) in the present study and this rate was similar in Rakowska et al.'s study in which they detected this sign in 11 of 44 (25\%) TTM cases [3]. Khunkhet et al. also detected flame hair in 10 of 23 TTM cases (43.5\%). Both of the previous studies stated that there is no case of AA showing flame hair.

Hair powder is almost totally damaged hair shaft which shows only sprinkled dots [3]. We detected hair powder in 13 (65\%) cases. This rate was considerably higher than in Rakowska et al.'s and Khunkhet et al.'s studies.

Follicle haemorrhages associated with traumatic forced plucking seem to be another strong clue to TTM which we detected in 8 (40\%) cases. Ise et al. suggested this finding as a unique dermoscopic sign for the detection of coexisting trichotillomania in alopecia areata. We also observed that follicular haemorrhage was associated with AA in one TTM case.

Yellow dot is an empty follicular opening filled with keratin/sebum and was initially considered to be a pathognomonic sign of alopecia areata [12-14]. But it is revealed that they can also be found in many conditions like androgenetic alopecia, dissecting cellulitis, chronic cutaneous lupus erythematosus (CCLE) and trichotillomania [13, 15-17]. Rakowska et al. detected yellow dots in $7 \%$ of TTM and $66 \%$ of AA cases [3]. These rates were $21.6 \%$ and $46.2 \%$ in Khunkhet et al.'s study, respectively [5]. We observed this finding in 11 (55\%) TTM cases. So it can be clearly said that yellow dots are quite non-specific to any entity including AA.
Exclamation mark hair has been known as a specific sign of alopecia areata for years $[18,19]$. We detected exclamation mark hair in 8 (40\%) cases of TTM. This rate was $14 \%$ and $26.1 \%$ in Rakowska et al.'s and Khunkhet et al.'s studies, respectively $[3,6]$. We believed that exclamation mark hair may cause misdiagnosis of AA. So it should be known that this is not an uncommon finding in TTM.

\section{Conclusions}

Here we have documented trichoscopic findings in Turkish TTM patients retrospectively. Trichoptilosis, $V$ hair and hair powder were the most frequent relatively specific findings. We tried to define novel findings that we named branched hair and concentric hair. We also detected Mace sign in 9 cases. This sign was previously described just in 3 cases in a case study. Angulated hair was also first described for TTM in the present study. Lack of a comparison group is the main limitation of the study.

\section{Conflict of interest}

The authors declare no conflict of interest.

\section{References}

1. Szepietowski JC, Salomon J, Pacan P, et al. Frequency and treatment of trichotillomania in Poland. Acta Derm Venereol 2009; 89: 267-70.

2. Rudnicka L, Olszewska M, Rakowska A. Trichotillomania and traction alopecia. In: Atlas of Trichoscopy. Rudnicka L, Olszewska M, Rakowska A (eds.). Springer-Verlag, London 2012; 257-75.

3. Rakowska A, Slowinska M, Olszewska M, Rudnicka L. New trichoscopy findings in trichotillomania: flame hairs, V-sign, hook hairs, hair powder, tulip hairs. Acta Derm Venereol 2014; 94: 303-6.

4. American Psychiatric Association. Diagnostic and Statistical Manual of Mental Disorders. $5^{\text {th }}$ ed. American Psychiatric Association; Washington DC 2013. 251-4.

5. Malakar S, Mukherjee SS. 'Mace sign' - a definitive sign of trichotillomania? Our Dermatol Online 2017; 8: 491-2.

6. Khunkhet S, Vachiramon V, Suchonwanit P. Trichoscopic clues for diagnosis of alopecia areata and trichotillomania in Asians. Int J Dermatol 2017; 56: 161-5.

7. Abraham LS, Torres FN, Azulay-Abulafia L. Dermoscopic clues to distinguish trichotillomania from patchy alopecia areata. An Bras Dermatol 2010; 85: 723-6.

8. Gallouj S, Rabhi S, Baybay H, et al. Trichotemnomanie associée à une trichotillomanie: intéręt diagnostique de la dermoscopie. Ann Dermatol Venereol 2011; 138: 140-1.

9. Lee DY, Lee JH, Yang JM, Lee ES. The use of dermoscopy for the diagnosis of trichotillomania. J Eur Acad Dermatol Venereol 2009; 23: 731-2.

10. Mathew J. Trichoscopy as an aid in the diagnosis of trichotillomania. Int J Trichology 2012; 4: 101-2.

11. Ankad BS, Naidu MV, Beergouder SL, Sujana L. Trichoscopy in trichotillomania: a useful diagnostic tool. Int J Trichology 2014; 6: 160-3.

12. Ise M, Amagai M, Ohyama M. Follicular microhemorrhage: a unique dermoscopic sign for the detection of coexisting 
trichotillomania in alopecia areata. J Dermatol 2014; 41: 51820.

13. Rudnicka L, Olszewska M, Rakowska A, Slowinska M. Trichoscopy update 2011. J Dermatol Case Rep 2011; 5: 82-8.

14. Inui S, Nakajima T, Nakagawa K, Itami S. Clinical significance of dermoscopy in alopecia areata: analysis of 300 cases. Int J Dermatol 2008; 47: 688-93.

15. Rudnicka L, Olszewska M, Rakowska A. Atlas of Trichoscopy - Dermoscopy in Hair and Scalp Disease. Springer, London 2012.

16. Abraham LS, Torres FN, Azulay-Abulafia L. Pistas dermatoscópicas para diferenciar a tricotilomania da alopecia areata em placas. An Bras Dermatol 2010; 85: 723-6.

17. Lima C dos S, Lemes LR, Melo DF. Yellow dots in trichoscopy: relevance, clinical significance and peculiarities. An Brasil Dermatol 2017; 92: 724-6.

18. Rudnicka L, Olszewska M, Rakowska A, Czuwara J. Alopecia areata. In: Atlas of Trichoscopy Dermoscopy in Hair and Scalp Disease. Rudnicka L, Olszewska M, Rakowska A (eds). Springer, London 2012; 205-20.

19. Abraham LS, Torres FN, Azulay-Abulafia L. Dermoscopic clues to distinguish trichotillomania from patchy alopecia areata. An Brasil Dermatol 2010; 85: 723-6. 